9. Egger J, Wilson J 1983 Mitochondrial inheritance in a mitochondrially mediated disease. N Engl J Med 309:142

10. Engel WK, Cunningham GG 1963 Rapid examination of muscle tissue. An improved trichrome method for fresh-frozen biopsy sections. Neurology 13:919

11. Ferrans VJ, McAllister HA, Haese WH 1976 Infantile cardiomyopathy with histiocytoid change in cardiac muscle cells. Report of six patients. Circulation 53:708

12. Fine PEM 1978 Mitochondrial inheritance and disease. Lance 2:659

13. Hubner G, Grantzow R 1983 Mitochondrial cardiomyopathy with involvement of skeletal muscles. Virchows Arch Pathol Anat 399:115

14. Kennaway NG, Buist NRM, Darley-Usmar VM, Papadimitriou A, DiMauro S, Capaldi RA, Blank NK, D'Agostino A 1984 Lactic acidosis and mitochondrial myopathy associated with deficiency of several components of complex III of the respiratory chain. Pediatr Res 18:000

15. Marquis NR, Fritz IB 1965 The distribution of carnitine, acetylcarnitine and carnitine acetyltransferase in rat tissues. J Biol Chem 240:2193

16. Morgan-Hughes JA, Darveniza P, Kahn SN, Landon DN, Sherratt RM, Land JM, Clark JB 1977 A mitochondrial myopathy characterized by a deficiency in reducible cytochrome $b$. Brain 100:617

17. Morgan-Hughes JA 1982 Defects of the energy pathways of skeletal muscle. In: Matthews WB, Glaser GH (eds) Recent Advances in Clinical Neurology, vol 3. Churchill-Livingstone, Edinburgh, p 1

18. Morgan-Hughes JA, Hayes DJ, Clark JB, Landon DN, Swash M, Stark RJ, Rudge P 1982 Mitochondrial encephalomyopathies. Biochemical studies in two cases revealing defects in the respiratory chain. Brain J05:553
19. Neustein HB, Lurie PR, Dahms B, Takahashi M 1979 An X-linked recessive cardiomyopathy with abnormal mitochondria. Pediatrics 64:24

20. Norum KR 1964 Palmityl CoA-carnitine palmityltransferase. Biochim Biophys Acta 89:95

21. Sengers RCA, TerHaar BGA, Trijbels JMF, Willems JL, Daniels O, Stadhouders AM 1975 Congential cataract and mitochondrial myopathy of skeletal and heart muscle associated with lactic acidosis after exercise. J Pediatr $86: 873$

22. Sottocasa GL, Kuylenstierna B, Ernster L, Bergstrand A, 1967 An electron transport system associated with the outer membrane of liver mitochondria. J Cell Biol 32:415

23. Spiro AJ, Moore CL, Prineas JW, Strasberg PM, Rapin I 1970 A cytochromerelated inherited disorder of the nervous system and muscle. Arch Neurol 23:103

24. Tripp ME, Katcher ML, Peters HA, Gilbert EF, Arya S, Hodach RJ, Shug AL 1981 Systemic carnitine deficiency presenting as familial endocardial fibroelastosis. N Engl J Med 305:385

25. Tzagoloff A 1982 Mitochondria. Plenum Press, New York

26. Waber LJ, Valle D, Neill C, DiMauro S, Shug, AL 1982 Carnitine deficiency presenting as familial cardiomyopathy: a treatable defect in carnitine transport. J Pediatr 101:700

27. Wharton DC, Tzagoloff A 1967 Cytochrome oxidase from beef heart mitochondria. Methods Enzymol 10:245

28. Witzleben CL, Pinto M 1978 Foamy myocardial transformation of infancy. Arch Pathol Lab Med 102:306

\title{
Pulmonary Function of the Reserpine and Isoproterenol Models of Cystic Fibrosis
}

\author{
R. L. BOYD, E. M. FRANCIS, M. T. FLETCHER, AND J. A. MANGOS \\ Department of Pediatrics, Pulmonary Division, University of Florida College of Medicine, \\ Gainesville, Florida 32610
}

\section{Summary}

Two experimental animal models exhibiting functional and morphologic changes of exocrine glands similar to those seen in patients with cystic fibrosis $(\mathrm{CF})$ have been reported in the rat: chronic stimulation with reserpine (Martinez et al. 1973 Pediatr. Res. 9:463, 470) and chronic stimulation with isoprenaline (Sturgess and Reid 1973 Br. J. Exp. Pathol. 54:388). We have studied the pulmonary function of these models induced by injecting rats subcutaneously with reserpine (RES, $0.5 \mathrm{mg} / \mathrm{kg} / \mathrm{day}$ ), isoproterenol (ISO, $25 \mathrm{mg} / \mathrm{kg} /$ day), or saline (Con, $1.0 \mathrm{ml} / \mathrm{kg} /$ day) for 6 days. Plethysmorgraphic measurements were made for functional residual capacity (FRC), airways resistance $\left(R_{\mathrm{aw}}\right)$, specific airways conductance $\left(\mathrm{sG}_{\mathrm{aw}}\right)$, phase difference between air flow rate and mean alveolar pressure (PD), frequency of breathing (f), and tidal volume $\left(V_{T}\right)$ of the anesthetized rats. In the RES and ISO rats, the $F R C, R_{a w}$ and $f$ were not different from Con values. The $P D$ was greater and the $V_{T}$ was less than Con values $(p<0.05)$. The results of both studies indicate uneven ventilation (increased

Received October 25, 1983; accepted February 10, 1984.

Address reprint requests to R. L. Boyd, Ph.D., Department of Pediatrics, Pulmonary Division, The University of Texas Health Science Center at San Antonio, 7703 Floyd Curl Drive, San Antonio, TX 78284.

This work was supported by grants from the Cystic Fibrosis Foundation and the University of Florida Biomedical Research Support Grant Fund and was presented in part at the annual meeting of the American Physiological Society, 1981.
PD) and penduluft (decreased $V_{T}$ ) consistent with maldistribution of resistance and/or compliances of the peripheral airways and/ or alveolar compartments. These physiologic effects can be related to the morphologic changes reported for the airways of rats under chronic adrenergic stimulation (ISO) and expected for rats under chronic catecholamines depletion (RES). Since peripheral airways involvement is usually the earliest pulmonary lesion found in CF, these studies indicate that the RES and ISO models may be representative of the early pulmonary involvement of CF.

\section{Abbreviations}

\author{
CF, cystic fibrosis \\ RES, reserpine \\ ISO, isoproterenol sulfate \\ Con, saline
}

$\mathrm{CF}$ is a genetic exocrinopathy which affects $1: 1600$ live births among Caucasians. Patients with CF presumably have morphologically normal lungs at birth, as seen in infants dying of meconium ileus (2). The earliest pulmonary lesions in CF are dilatation and hypertrophy of bronchial glands and goblet cells, as well as metaplasia of the bronchiolar epithelium followed shortly by mucous plugging of peripheral airways (17). Subsequently, a vicious cycle of obstruction, chronic infection, and more tissue damage ensues. 
The earliest manifestation of pulmonary dysfunction in CF is an abnormality in the distribution of ventilation resulting in increased alveolar-arterial oxygen differences. This may occur before any detectable changes in flow rates or lung volumes. Tests of peripheral airways function, such as frequency dependence of dynamic compliance or flow rates at low lung volumes, may also show abnormalities in CF patients in whom more standard ventilatory measurements are still normal. These observations are consistent with the concept that the initial pulmonary lesion is in the peripheral airways (17).

Laboratory research of this disease has been hampered by the lack of a naturally occurring equivalent in animals (5). While no genetic animal model for CF has been found, two methods of chemical induction of pathophysiologic and morphologic changes in rats resembling the exocrinopathies of $\mathrm{CF}$ have been developed by chronic administration of reserpine $(7,8)$ and isoproterenol $(6,14)$.

Reserpine is a catecholamine depleter which lowers noradrenaline content of salivary glands and other tissues (3). The reserpine model has been used in showing that alterations of sympathetic neurotransmitters result in: 1) obstruction and dilatation of the submaxillary gland ducts (7);2) elevation of concentrations of $\mathrm{Na}^{+}, \mathrm{Ca}^{2+}$, protein, and carbohydrates in saliva (8); 3) presence of a ciliotoxic factor in the saliva $(8) ; 4)$ elevation of concentrations of a specific glycoprotein (15) as well as total protein, lipid, and carbohydrate content (9) in lung lavage fluid; and 5) reduction in volume, flow rate, bicarbonate concentration, and chloride concentration of pancreatic secretions (12).

Isoproterenol is a sympathomimetic amine which has been shown to induce: 1) enlargement of parotid and submaxillary glands; 2) functional changes in parotid glands, such as increased $\mathrm{Na}^{+}$concentration in parotid saliva, increased viscosity of parotid saliva, and altered macromolecular composition by acrylamide gel electrophoresis; 3 ) the presence of ciliary dyskinetic activity in serum $(6) ; 4)$ hyperplasia of goblet cells in the trachea and at all levels of the bronchial tree; 5) hypertrophy of tracheal submucosal glands (14), and 6) increased lipid content in lavage fluid (10). These responses to reserpine and isoproterenol representative of CF led to this study, the objective of which was to determine the pulmonary function responses in these chemically induced models of CF.

\section{MATERIALS AND METHODS}

Male Sprague-Dawley rats were obtained from Charles River Breading Laboratories (Kingsport, NY) from a colony documented to be free of respiratory pathogens such as Mycoplasma pulmonis and Sendai virus. The rats were housed at the University of Florida Health Center Animal Resources Department in the quarantine area away from other animals for the duration of the study. The rats were fed commercial rat food and given water ad libitum. The rats were given six daily injections of RES $(0.5$ $\mathrm{mg} / \mathrm{kg} /$ day, $n=6$ ) similar to the regimen described by Martinez et al. ISO (7), $(25 \mathrm{mg} / \mathrm{kg} /$ day, $n=9)$ as described by Sturgess and Reid (14), or equivolume saline as controls (ConR, $n=6$; ConI, $n=9 ; 1.0 \mathrm{ml} / \mathrm{kg} /$ day). No injections were made on day 7 , and on day 8 the pulmonary function of each rat was measured.

The pulmonary function measurements were made by methods described previously from this laboratory (4). The tests included functional residual capacity (FRC, ml), FRC per kg body weight ( $\mathrm{sFRC}, \mathrm{ml} / \mathrm{kg}$ ), airway resistance $\left(\mathrm{R}_{\mathrm{aw}}, \mathrm{cm} \mathrm{H} \mathrm{H}_{2} \mathrm{O} / \mathrm{ml}\right.$ / $\mathrm{sec})$, specific airway conductance $\left(\mathrm{sG}_{\mathrm{aw}}, \mathrm{ml} / \mathrm{sec} / \mathrm{cmH}_{2} \mathrm{O} / \mathrm{sec} / \mathrm{ml}\right)$, phase difference between flow rate at the nose and mean alveolar pressure (PD, degrees), tidal volume $\left(\mathrm{V}_{\mathrm{T}}, \mathrm{ml}\right)$, and frequency of breathing (f, Hz).

A DuBois-type plethysmograph system (in which the animal breathed internal air only) was used to determine the $\mathrm{R}_{\mathrm{aw}}$ and $\mathrm{sG}_{\mathrm{aw}}$ of the anesthetized, spontaneously nose-breathing rats. This system has been described previously for use with rats of similar size (4). Briefly, the 1.1-liter water-jacketed plethysmograph was constructed from a $6-\mathrm{cm}$ i.d. $\times 39 \mathrm{~cm}$ long $\times 0.3 \mathrm{~cm}$ wall thickness Plexiglas tubing. A 10-torr pressure transducer (Barocel, Model 1173, Datametrics, Inc., Wilmington, MA 01887) was connected to the plethysmograph, which detected the change in pressure resulting from change in volume $\left(\mathrm{V}_{\mathrm{c}}, 0.026 \mathrm{ml} /\right.$ torr $)$ due to compression or expansion of intrathoracic gas during the respiratory cycle. Within the plethysmograph, a pneumotachometer (No. 0000 Fleisch, Dynascience, Blue Bell, PA) connected to an MP45; $\pm 50 \mathrm{~cm} \mathrm{H} \mathrm{H}_{2} \mathrm{O}$ pressure transducer (Validyne Engineering, Northridge, CA 91324) and an HP8805B amplifier (Hewlett-Packard, Waltham, MA 02154) was used to measure flow rate at the nose $\left(\dot{V}_{\mathrm{n}}, \mathrm{ml} / \mathrm{sec}\right)$. The frequency response of all channels of the system was flat through at least $7 \mathrm{~Hz}$. The animal breathed through the pneumotachometer via a silicone rubber facemask molded to the shape of the face. A seal between the face and mask was facilitated by depilitating the face with Neet (Whitehall Laboratories, Inc., New York) and forming a gasket with a dental adhesive (Super-Poligrip, Dentco, Inc., Jersey City, $\mathrm{NJ})$. The dead space volume of the facemask-pnuemotachometer-transducer system was $5.1 \mathrm{ml}$, as determined by the mehtod of Palecek (19). By appropriate valving, the same MP45 transducer was used to measure airway opening pressure $(\mathrm{PaO}, \mathrm{cm}$ $\mathrm{H}_{2} \mathrm{O}$ ). The $\mathrm{PaO}$ was measured during respiratory efforts after occluding the airway opening during an expiratory pause to determine thoracic gas volume as an index of FRC. Measurement of $\mathrm{R}_{\mathrm{aw}}$ requires that the animal breathe gas at or near conditions of alveolar temperature and $\mathrm{H}_{2} \mathrm{O}$ saturation. These conditions were established throughout the plethysmograph by flushing with warmed humidified air. Exchange of respiratory gases resulted in a net decrease in volume in the closed plethysmograph. Oxygen was therefore metered into the box at a constant rate adjusted to the net gas exchange rate of each rat to compensate for the volume decrease.

At testing, each anesthetized animal was placed prone in the plethysmograph with the face sealed in the face mask. The system was flushed with warmed humidified air for approximately 6 min. The flushing was stopped, the plethysmograph was closed, and the oxygen flow rate was adjusted to maintain box pressure at atmospheric. During spontaneous nose-breathing, three $\mathrm{V}_{\mathrm{c}}$ versus $\dot{V}_{n}$ tracings were displayed on a storage oscilloscope (Model 5103N, Tektronix, Beaverton, OR 97005) and photographed (Fig. 1). Each $\mathrm{V}_{\mathrm{c}}$ versus $\dot{\mathrm{V}}_{\mathrm{n}}$ tracing represents at least two breaths, after which the oscilloscope beam was turned off and repositioned to make the next tracing of at least two breaths. The "figure-eight" $\mathrm{V}_{\mathrm{c}}$ versus $\dot{\mathrm{V}}_{\mathrm{n}}$ tracings are analogous to the pressure versus flow curves described by Jaeger and Bouhuys (18) for cyclic variation of lung volume. During inspiration (first

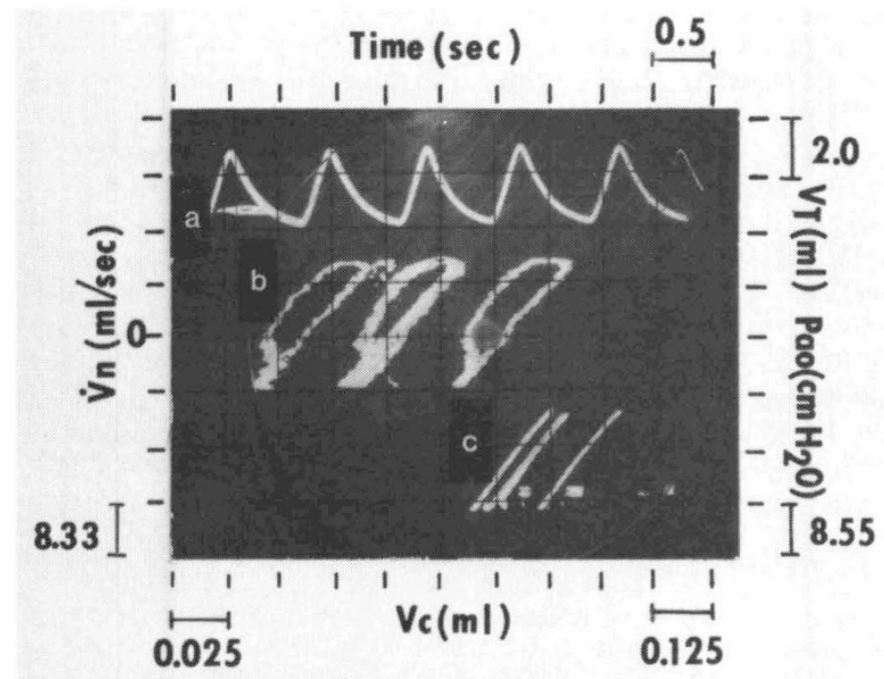

Fig. 1. $a$, time versus tidal volume; $b$, volume of compression of alveolar gas $\left(\mathrm{V}_{\mathrm{c}}\right)$ versus flow rate $\left(\dot{\mathrm{V}}_{\mathrm{n}}\right) ; c, \mathrm{~V}_{\mathrm{c}}$ versus pressure at the airway opening. 
quadrant), expansion of intrathoracic gas increases with increasing lung volume and flow rate and decreases at end inspiration as flow rate decreases to zero; then during expiration (third quadrant), compression of the gas occurs and during the end expiratory pause the $\mathrm{V}_{\mathrm{c}}$ versus $\dot{\mathrm{V}}_{\mathrm{n}}$ tracing returns to its origin. In normal animals, slight differences of the temperature and humidity of inspired gas from those of alveolar gas may result in a net expansion of intrathoracic gas at end inspiration. Measurements were made at a rectal temperature of $38.0^{\circ} \mathrm{C}$ with the air temperature at $38.25^{\circ} \mathrm{C}$. Measurements by this temperature regimen resulted in a net expansion of gas at end inspiration. Net expansion or compression of intrathoracic gas also occurs when $\dot{V}_{n}$ is out of phase with $V_{c}$ as a result of uneven distribution of ventilation $(1,4)$. The angle between the $\dot{\mathrm{V}}_{\mathrm{n}}=0$ on the $x$ axis, a line connnecting peak inspiratory $\dot{V}_{n}$ and peak expiratory $\dot{V}_{n}$ of each $V_{c}-\dot{V}_{n}$ tracing, was measured with a protractor mounted on the oscilloscope to determine their respective slopes. Using the slope of the $\mathrm{V}_{\mathrm{c}}$ versus $\dot{\mathrm{V}}_{\mathrm{n}}$ curve and Boyle's law to estimate alveolar pressure from $V_{c}$, the total airway resistance $\left(R_{a w}\right)$ was computed (4). Three independent $\mathrm{V}_{\mathrm{c}}$ versus Pao tracings (Fig. 1c) were obtained during respiratory efforts against the closed airway opening. The angle from the $x$ axis of the $\mathrm{V}_{\mathrm{c}}$ versus $\mathrm{PaO}$ tracings were measured with the protractor and the slopes determined. The FRC was computed from the slope of each $\mathrm{V}_{\mathrm{c}}$ versus Pao tracing and application of Boyle's law (4). The average of the three determinations was used as the data for each animal. Specific FRC (sFRC) was computed as FRC/body weight. Specific airway conductance $\left(\mathrm{sG}_{\mathrm{aw}}\right)$ was computed as $\left(1 / \mathrm{R}_{\mathrm{aw}}\right) / \mathrm{FRC}$.

The phase difference (PD) between $\dot{V}_{n}$ and mean alveolar gas pressure (derived by Boyle's law from $V_{c}$ ) is based on the concept of asynchronous filling and emptying of lung compartments (11) and is an index of uneven distribution of ventilation (1). The PD was calculated from the same $V_{c}$ versus $\dot{V}_{n}$ tracing used for $R_{a w}$ determination (Fig. $1 b$ ) as the arcsine of the ratio at $\mathrm{V}_{\mathrm{c}}$, at $\dot{\mathrm{V}}_{\mathrm{n}}=$ 0 , to the maximal $V_{c}$ during a breathing cycle (1). The tidal volume $\left(\mathrm{V}_{\mathrm{T}}, \mathrm{ml}\right.$; determined by integration of the $\dot{V}_{\mathrm{n}}$ with a HP8816A respiratory analyzer) was recorded against time on the storage oscilloscope and photographed (Fig. 1a). From this tracing, the $V_{T}$ and frequency of breathing $(\mathrm{f}, \mathrm{Hz})$ were measured. Data are reported as the mean \pm standard error and were analyzed by the analysis of variance and Student's $t$ test at the $p$ $<0.05$ level of significance (13).

\section{RESULTS}

Reserpine. The results of this study are shown in Table 1. These results show that the body weight in kilograms was significantly less in the RES rats compared to that of the ConR rats. The FRC of the RES rats was not different from that of the ConR rats, but, because of the depressed body weight, the SFRC was increased in the RES rats. The $R_{a w}$ of the RES rats was not

Table 1. Pulmonary function measurements of control, reserpine, and isoproterenol-treated rats

\begin{tabular}{|c|c|c|c|c|}
\hline & ConR* & RES & ConI & ISO \\
\hline$n \dagger$ & 6 & 9 & 9 & \\
\hline BW & $256 \pm 6 \ddagger$ & $165 \pm 6 \S$ & $282 \pm 4$ & $264 \pm 4 \S$ \\
\hline FRC & $5.1 \pm 0.3$ & $4.5 \pm 0.5$ & $5.6 \pm 0.3$ & $5.6 \pm 0.6$ \\
\hline sFRC & $19.7 \pm 1.0$ & $27.6 \pm 3.2 \S$ & $20.0 \pm 1.2$ & $21.4 \pm 2.4$ \\
\hline $\mathrm{R}_{\mathrm{aw}}$ & $0.41 \pm 0.04$ & $0.32 \pm 0.02$ & $0.42 \pm 0.03$ & $0.43 \pm 0.08$ \\
\hline$s G_{a w}$ & $0.50 \pm 0.03$ & $0.71 \pm 0.04 \S$ & $0.44 \pm 0.03$ & $0.49 \pm 0.04$ \\
\hline PD & $13.8 \pm 1.1$ & $22.8 \pm 0.90 \S$ & $9.4 \pm 1.6$ & $17.9 \pm 1.7 \S$ \\
\hline $\mathrm{V}_{\mathrm{T}}$ & $2.8 \pm 0.1$ & $2.3 \pm 0.05 \S$ & $3.0 \pm 0.1$ & $2.6 \pm 0.1 \S$ \\
\hline f & $1.5 \pm 0.07$ & $1.5 \pm 0.09$ & $1.6 \pm 0.05$ & $1.6 \pm 0.08$ \\
\hline
\end{tabular}

* Saline controls (ConR and ConI) for RES and ISO treated rats, respectively.

$\dagger n$, number of rats per group; BW, body weight $(\mathrm{g})$.

$\ddagger$ Mean \pm SE.

$\S$ Significant at $p<0.05$. different from ConR value. However, when normalized for lung volume at $\mathrm{FRC}$, the total $\mathrm{sG}_{\mathrm{aw}}$ was significantly increased, suggesting an enlargement of the caliber of central airways. The PD between flow rate and mean alveolar pressure of the RES rats was significantly increased, indicating uneven distribution of ventilation. The $f$ of the RES rats was not different from that of the ConR rats; whereas the $\mathrm{V}_{\mathrm{T}}$ was significantly lower in the RES rats.

Isoproterenol. Similar results were obtained in the ISO rats with decreased body weight but no change in FRC or sFRC as compared to the ConI rats values. Likewise, no differences were observed in $\mathrm{R}_{\mathrm{aw}}$ or $\mathrm{sG}_{\mathrm{aw}}$. However, the PD was greater in the ISO rats than in the ConI rats at the same $f$, but with reduced $V_{T}$.

Pulmonary function values for the ConR and ConI rats were similar to those reported previously for control rats (4).

\section{DISCUSSION}

The pulmonary function in these two proposed models of cystic fibrosis using reserpine-treated rats and isoproterenoltreated rats was affected primarily by uneven distribution of ventilation. The methodology for studying distribution of ventilation was based on the concept of distribution of time constants in the peripheral airway-alveolar compartments (11). The two principal determinants of the relationship of flow rate to mean alveolar pressure are the resistance of the peripheral airways and compliance of the alveoli. In this study, since the FRC of the treated rats was not different from that of the control rats, there is no indication that the pulmonary compliance was affected by the reserpine or the isoproterenol treatment. Subsequently, the determinant component for the observed differences in distribution of ventilation is expected to be inequality of the peripheral airways resistance.

Changes in peripheral resistances would be expected from the morphologic alteration of the bronchiolar epithelial cells and glands due to treatment with isoproterenol as described by Sturgess and Reid (14). While no morphological alteration to the airway epithelium of reserpine-treated rats has been previously reported, the data from this study indicating uneven distribution of the time constants would suggest that such alterations would result from reserpine treatment.

The magnitude of the phase difference has been demonstrated mathematically to be frequency-dependent $(1,4)$. However, the frequency of breathing of the treated rats was the same as that of the control rats. The higher phase difference of the treated rats, therefore, would reflect an uneven distribution of time constants without frequency interference. It has also been demonstrated that the magnitude of the phase difference at a given frequency is more sensitive to inequality of peripheral resistances than to inequality of peripheral compliances (1). This is consistent with the physiologic interpretations that we have made in this study.

The reduced tidal volume in both models is consistent with penduluft or movement of some gas between alveolar compartments as the alveolar pressures equilibrate between breaths (11). Another interpretation of the reduced tidal volume could be hypoventilation in the anesthetized rats. However, since sodium pentobarbital was the anesthetic used, an increased responsiveness would be expected to cause hypoventilation by decreased frequency. But since frequency of breathing was not affected, penduluft appears to be the more logical mechanism for the reduced tidal volume.

In patients with cystic fibrosis, one of the earliest indications of pulmonary function impairment is an abnormality in distribution of ventilation resulting in increased alveolar-arterial oxygen differences (17). This is consistent with the concept that the initial pulmonary lesion in cystic fibrosis is in the peripheral airways (5). PD measurements made in the two animal models of this study similarly indicate peripheral airways involvement resulting in inequality of time constants which causes uneven distribution of ventilation. Based on these interpretations, the results of this study provide additional evidence that the reser- 
pine-treated rat and the isoproterenol-treated rat may be appropriate models for laboratory study of the pulmonary involvement of cystic fibrosis, particularly of the early pulmonary lesions which affect the peripheral airways.

While these pharmacologic manipulations result in glandular function abnormalities in rats similar to those observed in patients with $\mathrm{CF}$, it is clear that the disease cystic fibrosis is not induced in these animals. Rather, two model systems are induced with particular physiologic or histologic characteristics similar to CF. By studying these models, a better understanding of the mechanisms of cellular function leading to the physiologic or morphologic abnormalities may be gained.

Since abnormalities in peripheral airway function in $\mathrm{CF}$ patients leads to pregressive deterioration of pulmonary sufficiency, it is important to understand the relationship of structural changes to progressive changes in pulmonary function. Use of these models with the pulmonary function measurement procedures described in this report in conjunction with histologic analysis of airways during progression or regression of the induced alterations would facilitate correlation of structure-function relationships. A better understanding of the extent of airway alteration required to affect pulmonary function could be gained from such studies. Knowledge gained from studies with these model systems may lead to an improved interpretation of clinical pulmonary function findings in CF patients or at least a better appreciation for the sensitivity of the measurement procedures.

Moreover, this study showed that phase difference between air flow rate and mean alveolar pressure was sensitive to peripheral airways alterations when tests for large airways function $\left(R_{a w}\right)$ and resting lung volume (FRC) showed no abnormalities. The PD as an index of distribution of ventilation may, therefore, be useful in evaluation of the pulmonary status of CF patients. In view of the minimal cooperation required by the subject, this methodology adapted to children could yield valuable information when other less sensitive or more patient cooperation dependent methods are not practical.

\section{REFERENCES}

1. Banerjee M, Evans JN, Jaeger MJ 1976 Uneven ventilation in smokers. Respir Physiol 27:277
2. Bedrossian CWN, Greenberg SD, Singer DB, Hansen JJ, Rosenberg, HS 1976 The lung in cystic fibrosis: a quantitative study including prevalence of pathologic findings among different age groups. Human Pathol 7:195

3. Benmiloud M, von Euler US 1963 Effects of bretylium, reserpine, guanethidine and sympathetic denervation on the noradrenaline content of the rat submaxillary gland. Acta Physiol Scand 59:34

4. Boyd RL, Jaeger MJ, Fisher MJ 1980 Noninvasive lung function tests in rat with progressive papain-induced emphysema. Respir Physiol 40:181

5. Di Saint'Agnese PA, Davis PB 1976 Research in cystic fibrosis. N Engl J Med 295:481, 597

6. Mangos JA, McSherry NR, Benke PJ, Spock A 1969 Studies on the pathogenesis of cystic fibrosis: the isoproterenol treated rat as an animal model. In 5th International Cystic Fibrosis Conference (Cambridge), Sept 1969, paper 3

7. Martinez JR, Adelstein E, Quissel DO, Barbero GJ 1975 The chronically reserpinized rat as a possible model for cystic fibrosis. I. Submaxillary gland morphology, and ultrastructure. Pediatr Res 9:463

8. Martinez JR, Adshead PD, Quissel DO, Barbero GJ 1975 The chronically reserpinized rat as a possible model for cystic fibrosis. II. Composition and cilioinhibitory effect on submaxillary saliva. Pediatr Res 9:470

9. Mawhinney TP, Feather MS, Martinez R, Barbero GJ 1979 The chronically reserpinized rat as an aminal model for cystic fibrosis. III. Acute effects of isoproterenol and pilocarpine upon pulmonary lavage fluid. Pediatr Res 13:760

10. Mawhinney TP, Martinez R, Feather MS, Barbero GJ 1980 Composition of pulmonary lavage fluid in control and reserpine-treated rats following chronic isoproterenol and pilocarpine administration. Pediatr Res 14:872

11. Otis AB, McKerrow CB, Bartlett RA, Mead J, McIlroy MB, Selverstone JJ Radford EP 1956 Mechanical factors in distribution of pulmonary ventilation. J Appl Physiol 8:427

12. Perlmutter J, Martinez JR 1978 The chronically reserpinized rat as a possible model for cystic fibrosis. VII. Alterations in the secretory response to cholescystokinin and to secretin from the pancreas in vivo. Pediatr Res 12:188

13. Steel RGD. Torrie JH 1960 Principles and Procedures of Statistics. McGrawHill Book Co., New York, p 43

14. Sturgess J, Reid J 1973 The effect of isoprenaline and pilocarpine on (a) bronchial mucus-secreting tissue and (b) pancreas, salivary glands, heart, thymus, liver and spleen. Br J Exp Pathol 54:388

15. Thompson FE, Quissel DO, Williams CH, Martinez JR 1976 The chronically reserpinized rat as a possible animal model for cystic fibrosis. IV. The protein composition of pulmonary lavage fluid. Pediatr Res 10:632

16. Wood DL, Martinez JR 1977 The chronically reserpinized rat as a possible animal model for cystic fibrosis. VI. Synergistic effects of isoproterenol on $\mathrm{Ca}^{++}$and protein in the submaxillary gland. Pediatr Res 11:827

17. Wood RE, Boat TF, Doershunk CF 1976 Cystic fibrosis: state of the art. Am Rev Resp Dis 113:833

18. Jaeger MJ, Bouhuys A 1969 Loop formation in pressure vs. flow diagrams obtained by body plethysmographic techniques. Prog Respir Res 4:116

19. Palecek F 1969 Measurements of ventilatory mechanics in the rat. J Appl Physiol 27:149 